\title{
Análisis jurídico-diplomático de las Ordenanzas Reales de Bujía de 1531
}

\author{
Ángel Riesco Terrero *
}

\section{DEL FUERO MEDIEVAL A LAS ORDENANZAS MODERNAS}

La promulgación de normas juridicas de ámbito local en núcleos urbanos y rurales pertenecientes a la Corona, a grandes señoríos y aun a autoridades e instituciones de carácter militar, muncipal, eclesiástico, gremial, etc. dio lugar a los célebres fueros medievales que, junto con los privilegios, exenciones, franquicias, costumbres, cartas de población..., juegan un papel importante durante la repoblación y organización de los respectivos poblados y asentamientos de los siglos XI-XIII.

Mediante esta normativa de ámbito local o territorial limitado-plasmada en el derecho consuetudinario y local y aplicada no sólo a un núcleo principal de población sino también a su territorio circundante o alfoz e igualmente a las tierras y poblados mancomunados e interdependientes, pero formando una demarcación, comarca, partido, sexmo, jurisdicción, plaza fuerte, etc., se administraron y gobernaron numerosos pueblos y localidades castellano-leonesas.

Desde el siglo Xv el sistema foral y los derechos locales experimentan una fuerte crisis. Los nuevos fueros, principalmente concejiles, suelen ser copias repetitivas de los anteriores con ciertos recortes y adaptaciones a las peculiaridades de las ciudades, villas y pequeñas aldeas para quienes se confeccionaron y concedieron. Basta leer los fueros de Ronda, VélezMálaga, Baza, Almuñécar, Guadix, Málaga... para convencerse de que su entramado normativo y organización jurídico-administrativa responden, bien al nuevo modelo de los fueros y ordenamientos reales, dados por los monarcas o sus representantes a una ciudad concreta, que después,

\footnotetext{
* Catedrático de la Universidad Complutense.
} 
tal vez, se amplía a otras, v. gr. Algeciras, Alicante, Córdoba, Sevilla, Burgos, Medina del Campo..., bien a otro más amplio y general, diseñado por los Reyes Católicos y sus inmediatos sucesores para las distintas ciudades, villas, enclaves estratégicos y lugares recién incorporados a la Corona (tanto en España como en África e Indias) y, ciertamente, necesitados de ordenación jurídica, administrativa y territorial.

A raiz de la conquista de Granada e incorporación a Castilla del Archipiélago Canario y, sobre todo, a partir de 1500, el derecho local, expresión conjunta de los distintos poderes y jurisdicciones y símbolo, en cierto modo, de la autonomía, exención y privilegio, regulado hasta ahora por la Corona y sus representantes o por autoridades convergentes: señores, concejos, cabildos, corregidores, compromisarios..., va a perder, al menos parcialmente, su carácter de norma fundamental, aunque en la mayoría de los casos no alcanzará otra categoría sino la de reglamentación complementaria, en orden a determinados puntos: administración local, comercio, pacífica convivencia, etc. para pasar definitivamente a norma subsidiaria de las leyes generales en aspectos o puntos muy concretos, con frecuencia no contemplados o poco desarrollados en dichos ordenamientos.

Sentadas las bases para una nueva ordenación jurídico-territorial (repartimientos) de los distintos pueblos y tierras del viejo reino de Granada, se hacía preciso reorganizar, sistematizar y recopilar con nuevos criterios todo lo legislado, adecuando la normativa local: vieja y nueva, a la politica y necesidades del momento.

Los «fueros nuevos» (siglo xv y principios del xv1), reminiscencia y última expresión de los antiguos fueros medievales, pero de ámbito jurisdiccional bastante más reducido que éstos, van a dar paso, en la época de D. Juana y del emperador, a un nuevo tipo de instrumento jurídico de régimen administrativo local: las Ordenanzas, con valor no de ley privilegiada, aunque fuera territorial o local, sino más bien de reglamento, ordenación y regulación de distintos aspectos de la vida: convivencia, trabajo, comercio, salarios, actividades, derechos y obligaciones, economía, urbanismo, obras de reconstrucción y defensa, gestión administrativa, etc.

\section{ORDENANZAS: MAYORES Y MENORES, REGLAMENTOS, ESTATUTOS}

Los concejos, que creyeron encontrar en los «fueros nuevos» la expresión normativa de sus poderes más genuinos, no gozaban ya del antiguo protagonismo político y su capacidad y libertad, en el campo legis- 
lativo, eran más bien escasas. Prueba de ello es la exclusión total en el artículado de sus ordenanzas de los aspectos más interesantes del Derecho civil y penal, regulados en los ordenamientos (Código) generales. La vigencia de estos «fueros nuevos» y «ordenanzas" de los siglos XV-XVI, -en su mayoría no reales, de origen principalmente concejil, señorial o gremial- se debe, no a los municipios o a sus representantes: corregidores, justicias, bailes, procuradores, jueces de residencia, alcaides, virreyes y gobernadores (Hispanoamérica)..., ni siquiera a los titulares y dueños del señorio que los elaboraron. Su valor jurídico dependia fundamentalmente de la aprobación real explícita o, al menos, del refrendo y visto bueno dado por los altos organismos del Gobierno, principalmente el Consejo Real.

Aun en los casos en que no aparece la aprobación o confirmación explícita por parte de la autoridad real de estos "fueros nuevos" y "ordenanzas modernas", suelen incluirse en ellos algunas cartas y provisiones reales con la consiguiente advertencia y señalación de los puntos en que dicha reglamentación local debe atenerse a la ley general.

Esta nueva reglamentación y actividad legislativa de ámbito local, concejil, gremial..., limitada a aspectos fiscales, mercantiles, económicos, laborales, defensivos, urbanísticos, militares, etc., por lo general de procedencia no unitaria, se va a configurar, bien a base de normas dictadas exclusivamente por la Corona: Rey y Cortes, en cuyo caso se denominan "Ordenanzas reales», bien mediante una reglamentación emanada a lo largo del tiempo por el propio concejo, comunidad o institución y sus legítimos representantes, pero aprobada y promulgada posteriormente por los monarcas o por sus delegados.

A la hora de reglamentar mediante ordenanzas locales la organización de distintos aspectos de la vida y actividades de diversos pueblos y territorios, los autores tuvieron a la vista, de una parte, la legislación general (Cuerpos legislativos generales), que ellos completan con normas prácticas tomadas de la jurisprudencia y resoluciones dictadas por los tribunales superiores: Cancillerías y Audiencias, sobre asuntos concretos $y$, de otra, los privilegios y provisiones reales anteriores y posteriores a las ordenanzas locales, sin omitir, finalmente, viejas disposiciones procedentes de usos y costumbres antiguas, todavía con fuerza jurídica y vigencia local.

Estas ordenanzas (ordenamientos, ordenaciones), más tarde estatutos, reglamentos, etc. procedentes de los propios concejos, comunidades e instituciones y, más concretamente, de sus titulares y representantes - confirmadas o no por los reyes - reciben el calificativo de "Ordenanzas u Ordenamientos»: municipales, gremiales, concejiles, militares, etc. de 
tal comunidad, tierra, ciudad, villa, pueblo, lugar o plaza, reduciéndose su alcance - como dije antes - más al establecimiento de un orden de vida y regulación de distintos aspectos y actuaciones de ámbito militar, mercantil, agrario, laboral, urbanístico, fiscal, administrativo, etc. que a los planos de la legislación y gobierno propiamente dichos.

El alcance normativo de muchas de estas ordenanzas, reglamentos, estatutos y fueros locales de los siglos XVI-XVIII aplicados, por lo general, a un solo pueblo, plaza, lugar o grupo de pueblos vinculados entre sí por razones de origen, proximidad, intereses comunes, productividad y explotación (comunidad, comarca, zona, nacionalidad, etc.) es tan reducido y puntual que realmente no merecen otro calificativo que el de ordenamientos jurídico-administrativos de grado menor $u$ ordenanzas de segunda clase.

Este tipo de normas, designadas con el calificativo de reglamentos, estatutos, acuerdos, ordenamientos, posturas y capítulos de ordenanzas, cuadernos de leyes, ceremonias y usos..., no pasan de ordenanzas de segundo grado o menores. En su mayoría, proceden de concejos, comunidades, gremios, señores..., y no son producto de un solo autor ni se promulgaron una sola vez. Con frecuencia, su articulado no es cerrado sino abierto y susceptible de nuevas disposiciones que lentamente se irán incorporando y promulgando, bien por el rey, bien por sus delegados: corregidores, alcaides, jueces de residencia, etc. Esto es lo que ocurre con estas Ordenanzas reales de Bujía de 1531, de carácter militar e incrementadas con nueva reglamentación por D. Alejo Salgado Correa y D. Luis Peralta entre 1526-1540 ${ }^{1}$.

Si bien es cierto que algunas de estas ordenanzas menores vieron la luz pública, su promulgación e impresión en el momento de nacer, otras, en cambio, permanecieron durante largo tiempo en la categoría de usos

\footnotetext{
1 La doctora M. $^{*}$ T. López Beltrán, titular de Historia Medieval de la Universidad de Málaga, publicó en 1984 (Baetica, vol. 7, págs. 219-244) las Ordenanzas de Bujia (1536-1540). Considero acertado el juicio emitido por la profesora Beltrán cuando afirma que se trata de la reglamentación interna de una plaza norteafricana de gran importancia por su condición de enclave fronterizo, su función defensivo-militar, alto núcleo de población existente y vida urbana relativamente desarrollada. No es cierto, en cambio, que Bujia no disponga de ordenanzas hasta el año 1536, puesto que las otorgadas por D. Juana y D. Carlos están fechadas en Ocaña, el 10 de mayo de 1531, y no me sorprenderia que con anterioridad (entre 1510-1525) nuestros monarcas - dada la densidad de población civil y militar, los excesos cometidos y la mala gestión de los alcaides y personal administrativo de dicha fortalezahubieran tomado las medidas pertinentes para regular, mediante provisiones reales, cédulas, pragmáticas y otros documentos a modo de ordenanzas, la convivencia pacifica, el buen gobierno de la actividad cotidiana y, sobre todo, la disciplina y servicio militar de los hombres de guerra destacados en aquella plaza y guarnición.
} 
y costumbres y sólo alcanzaron el rango de normativa pública local tras largo periodo de vigencia o en época bastante posterior a sus orígenes.

Al lado de los fueros y ordenamientos locales de distinta proveniencia y alcance jurisdiccional, surgen en España e Hispanoamérica (siglos xvXVII) otros tipos de disposiciones reales, ordenanzas, reglamentos, estatutos etc., de carácter unitario y con normativa específica para la protección, regulación, explotación y fomento de determinados sectores y asuntos relacionados con la minería, industria, ganaderia o cualquier otro problema. No existe, sin embargo, un documento único tipificado para la tramitación de estos asuntos, sino que se recurre a varios: Órdenes, disposiciones, circulares, reglamentos...

Gracias a la publicación y estudios de numerosas ordenanzas, estatutos, reglamentos, etc., este tipo de legislación y fuente documental resulta familiar y cómoda a historiadores, juristas y filólogos. Quedan, no obstante, muchas aún inéditas, cuando no ocultas, entre libros y legajos de nuestros grandes y pequeños archivos: civiles, eclesiásticos, señoriales y de instituciones. Entre éstas figuran las «Ordenanzas reales de Bujía» dadas a dicha ciudad y fortaleza militar por doña Juana I y su hijo el emperador don Carlos, el 10 de mayo de 1531, veintiún años después que el Rey Católico conquistara la citada plaza y presidio ?

${ }^{2}$ La abundante bibliografia existente sobre ordenanzas, estatutos, reglamentos, ordenaciones locales... (sobre todo castellanas), de origen real, señorial, municipal, eclesiástico y gremial, me exime de dar un largo listado con los títulos de las mismas y nombres de los estudiosos que profundizaron en ellas o las dieron a conocer. Como botón de muestra, cito los trabajos del profesor LADERo QUESADA, «Ordenanzas municipales y regulación de la vida económica de Andalucía y Canarias. Siglos Xiv-XVII"s, publicado en II Coloquio de Historia Canario-Americana. Gran Canaria 1979, págs. $143-156$ y otro trabajo del propio LADERO, M. A., y de Galan Parra, I., "Las Ordenanzas locales en la Corona de Castilla como fuente histórica y tema de investigación (siglos $\mathrm{x} \|$ al $\mathrm{xV} \| 1$ )», con abundante bibliografía en notas, publicado en Anales de la Universidad de Alicante. Historia Medieval, n. ${ }^{\circ}$. Alicante 1982, págs. 221-243. Otros puntos de referencia raás reciente pueden ser: El ordenamiento de Algeciras (a. 1345) de Torremocha Silva, A., Algeciras 1983; las Ordenanzas del Concejo de Málaga. Málaga 1989, de Arroyal, P. J. y Espigares y Martín Palma, M. ${ }^{a}$ T., las Ordenanzas Municipales de Alicante, de Alberola, A. y Paternina, M. ${ }^{a}$, Alicante 1989, y El Llibre del «mustacaf" de la ciutat d'Alacant. Alicante 1989, de Cabanes CATALA, M. ${ }^{a}$ L. Por su interés histórico-jurídico y las valiosas noticias que ofrecen sobre el tema, cito también los trabajos de Corral Garcia, E., Ordenanzas de los Concejos castellanos. Formación, contenido y manifestaciones (siglos XIII-XVIII). Madrid 1981; LALINDE ABADIA, J., Iniciación histórica al Derecho español. Barcelona 1979 y «El derecho castellano en Canarias» publicado en Anuario de Estudios Atlánticos, 16 (1970) págs. 18-35; Garcia GaLlo, A., "Aportación al estudio de los fueros", AHDE, 1956, págs. 387-446; GISBERT, R., «El Derecho municipal de León y Castilla", AHDE, 1961, págs. 695-758; Pérez Prendes, J. M., Curso de Historia del Derecho español. Madrid 1970, págs. 18-35 y «El Derecho municipal del Reino de Granada», Revista de Historia del Derecho. Granada 1977-78, vol. II, 1, págs. 371-459 y, finalmente, las obras de Pérez 
El estudio de estas Ordenanzas reales gira en torno a estos puntos: a) Análisis juridico; b) Estructura documental; c) Reglamentación específica en relación con el articulado del texto original conservado en el Archivo General de Simancas y d) Conclusiones.

\section{ASPECTOS POLITICO-JURIDICO Y PUNTOS DE CONTACTO ENTRE LAS ORDENANZAS REALES, LAS PROVISIONES Y LAS PRAGMÁTICAS}

Si bien es cierto que las cancillerias, curias y demás órganos de expedición documental moderna, a partir del siglo xIIl, acostumbran a utilizar instrumentos jurídicos concretos y diplomas específicos para los distintos asuntos o para conjuntos de negocios similares en cuanto a procedencia, negocio, solemnidad y destinatario, sin embargo, no es raro encontrar documentos de gran categoría diplomática (solemnidad) y aun jurídica (autor, contenido e importancia de lo tramitado), expedidos mediante diplomas de nivel medio o ínfimo y viceversa. Existen, por ejemplo, concesiones menores, donaciones y privilegios simples, mercedes, notificaciones..., expedidos mediante provisiones o cédulas reales que son mucho más solemnes y de mayor alcance que las cartas de merced, los albalaes y otras cartas regias: abiertas o cerradas que, según la legislación y normativa cancilleresca del Fuero Real, Las Partidas, etc., eran las más adecuadas para la tramitación de este tipo de negocios.

El propio título y denominación de la acción y asunto o negocio a realizar: sentencia, testamento, donación, orden..., y su formulación dispositiva v. gr. «otorgo», «mando», «ordeno», "dispongo», "concedo»..., en unos casos, no es elemento determinante, a veces, ni siquiera clasificador y, en otros, o no responde a la naturaleza del asunto documentado, o resulta inadecuado, inexacto o sólo parcialmente verdadero.

Razones de distinta índole: la naturaleza reservada o secreta del asunto, para mayor seguridad, por urgencia, el deseo de complacer a los solicitantes y agraciados (rogatarios), la vía y sistema de expedición adoptados, la voluntad y decisión personal de los monarcas y artífices de la documentación y mil circunstancias más, fueron factores determinantes de estas aparentes $y$, a veces, reales anomalías.

Prendes, J. M.-Azcáraga J. de, Lecciones de Historia del Derecho Español. Madrid 1989, págs. 184-195 y la de Barrero Garcia, A. M. ${ }^{2}$-Alonso Martín, M. ${ }^{2}$ L., Textos de derecho local español en la E. Media. Catálogo de Fueros y costums municipales. Madrid 1989. 
Desde el punto de vista jurídico-diplomático las Ordenanzas de Bujía de 1531 están ya bastante lejos de los clásicos fueros y ordenamientos jurídicos locales (siglos $x$-xII) otorgados, bien directamente por el rey y grandes señores, bien a ruego de los súbditos y concejos, para regular la vida ciudadana, organización y actividades laborales, administrativas y comerciales, tanto de los municipios y mancomunidades como de sus habitantes.

La concesión de este tipo de ordenamientos de carácter local y privilegiado no fue casual sino más bien una exigencia circunstancial atribuible, en unos casos, a la política del momento y a la situación de numerosas ciudades y territorios recien conquistados a los musulmanes y, en otros, a los nuevos núcleos de población desplazados desde sus lugares de origen con grandes peligros e inseguridad a aquellas tierras renacientemente anexionadas y sometidas a nueva legislación y autoridad.

Al derecho local de una ciudad, villa, pueblo o comarca, recogido por escrito o meramente consuetudinario y, por lo general, con varias etapas de elaboración y distintas relaciones, que gozó desde tiempos antiguos de cierto reconocimiento en cuanto regulador total o parcial de determinados aspectos de la vida: convivencia, comercio, economía, justicia, administración... se denominó «fuero», "costumbre», "privilegio», "carta de población», «franquicia», «inmunidad», etc. Términos excesivamente genéricos $y$, a veces, equívocos, máxime cuando se desconoce el alcance jurídico de dichos textos y, sobre todo, cuando se aplica indistintamente a cualquier tipo de regulación - provenga de donde sea- de carácter local, institucional o personal, tanto si corresponden al medievo como a las épocas renacentista y moderna.

En las ordenanzas y demás ordenamientos modernos (siglos xIV y siguientes) de origen real, municipal o señorial, pero con respaldo y aprobación del rey, e igualmente en algunas cartas de población tardías y en los llamados "fueros nuevos", «estatutos y normas de asentamiento", etc., utilizados por los Reyes Católicos y autoridades delegadas en la repoblación del reino de Granada e Islas Canarias, la normativa consuetudinaria local y concejil se ve sustituida por conjuntos de leyes de carácter territorial y de mayor amplitud en cuanto a aspectos regulados, penalizados, etc.

La intervención directa o al menos indirecta del rey, que aprueba y promulga estos ordenamientos de origen y elaboración diversa, se debe, en unos casos, a las tensiones producidas entre los distintos estamentos sociales configurativos del municipio o comunidad; en otros, a la politica regia de control y restricción de la capacidad legislativa de los concejos, mancomunidades e instituciones $y$, finalmente, a otras necesidades cir- 
cunstanciales, v. gr. cubrir posibles lagunas legislativas no contempladas en los fueros y ordenamientos viejos, distinguir y premiar con ordenamiento propio los servicios prestados por una comunidad o, simplemente, atraer hacia determinadas zonas fronterizas, despobladas o en periodo de desarrollo y reorganización agrícola, ganadera, industrial, comercial, militar... un crecido número de habitantes, soldados, labriegos, comerciantes, artesanos, etc., interesados por las ventajas de un régimen juridico territorial privilegiado y ventajoso.

Desde el punto de vista diplomático y aun jurídico, las Ordenanzas reales que $D^{\text {a }}$ Juana, en nombre propio y en el de su hijo el Emperador, da a la ciudad y fortalezas de Bujía en mayo de 1531, cabalgan a caballo entre los «fueros nuevos" y los "ordenamientos de leyes territoriales" de derecho mercantil, administrativo o militar, dadas en Cortes a partir del siglo XV. Pero quizás los diplomas más próximos a estas disposiciones reglamentarias sean las provisiones reales y pragmáticas, instrumentos jurídicos de uso corriente, especialmente en el siglo xVI, mediante los cuales la autoridad real y sus Consejos regulan y solventan gran parte de los asuntos administrativos de gobierno, gracia y justicia.

Por la provisión real, nuestros monarcas y, en su nombre, los Consejos, Audiencias y altos tribunales tramitaron por espacio de tres siglos (siglos $x V$ - $x$ VII) los asuntos más importantes de la administración y gobierno del reino. Hay que advertir, no obstante, que las provisiones en cuanto disposiciones preceptivas suelen ceñirse a un punto o asunto principai, con proyección, tal vez, a algunos más relacionados con aquél, pero nunca constituyen conjuntos de leyes destinadas a la regulación general de los complejos problemas y actividades que afectan a un pueblo, a una fortaleza militar o institución gremial. Estos actos de gobierno, casi siempre, requerían información previa y se hacian a petición o instancia de parte. Por lo general, iban redactados en forma ejecutiva de precepto o mandato $y$, en cuanto a extensión, son mucho más cortos que los fueros $y$ ordenamientos modernos.

Las pragmáticas, en cambio, son disposiciones u órdenes más o menos amplias y generales (territoriales) de carácter legislativo pero no reglamentista. En éstas predomina más el interés general de su contenido y cumplimiento que la amplitud de su ámbito territorial y esfera legislativa. Casi siempre se daban a petición de las Cortes pero sin intervención directa de las mismas y con fuerza de leyes aprobadas en Cortes. Comparadas con otros documentos legislativos mucho más modernos y fijándose en su carácter de ley o conjunto de leyes de mayor o menor importancia (ordenamiento), las pragmáticas sanciones, con su amplia 
exposición de motivos, articulado, promulgación, cláusulas conminatorias, data y validación, se asemejan bastante a los Reales Decretos y a los Decretos-Leyes.

Las ordenanzas propiamente dichas y de mayor rango jurídico, es decir, las de origen real y las respaldadas con el refrendo y promulgación de la Corona, de las Cortes, del Consejo Real, etc., cuya autoría se debe más bien a compromisarios, delegados y representantes de ciudades, villas e instituciones gremiales, constituyen una especie de ordenamiento, estatuto o norma legal de régimen jurídico-administrativo en el que, aparte de contemplarse los intereses locales y territoriales consignados en fueros y normas precedentes, se introducen reformas, se subsanan defectos graves, se cubren las lagunas existentes en determinados campos del derecho general y sistema jurídico castellano y, sobre todo, se salvan situaciones especiales en presidios y plazas fuertes carentes de régimen jurídico propio, máxime cuando tales enclaves se hallan alejados del territorio nacional y, por su situación fronteriza, amenazados por el peligro musulmán.

Aunque el cumplimiento de todas y cada una de las disposiciones establecidas en las ordenanzas de primer grado obliga con carácter legislativo-penal a cuantos están sometidos a dicho régimen jurídico-administrativo y disciplinar, sin embargo predomina con mucho el aspecto reglamentista y subsidiario respecto de la legislación general.

La unificación, reforma y renovación de un sistema juridico previo y, probablemente, envejecido a lo largo de 20 años y la salvaguarda en Bujía de los intereses tanto locales y personales como nacionales y, sobre todo, la necesidad apremiante de hacer - por razones políticas y defensivas - más eficaz dicha plaza y corregir en ella los graves defectos, injusticias y desórdenes detectados en el sistema administrativo, militar, de convivencia y justicia..., eran razones más que suficientes para que nuestros monarcas se considerasen obligados a dar a esta ciudad y fortaleza un ordenamiento juridico propio: las Ordenanzas de 1531, en virtud de las cuales los súbditos de este territorio, los oficiales y el resto de la tropa alli destacada, aparte de la legislación general común a todo el reino, gozasen de un ordenamiento peculiar complementario, de ámbito territorial e institucional, regulador de determinados aspectos relativos a la defensa y seguridad de la plaza, vida militar, convivencia, servicios, comercio, administración, salarios, diversiones, vicios, etc.

Mediante esta normativa, compuesta de 57 artículos, se contemplan determinados aspectos locales, territoriales y personales de un enclave fronterizo estratégico, situado al norte de Argelia, y de singular importancia para los planes expansionistas del Emperador, para el control de las 
aguas del Mediterráneo y defensa de nuestras fronteras. Nuestros monarcas, en calidad de legisladores y gobernantes, desarrollan y completan una serie de disposiciones, vigentes, sin duda, en ordenamientos y provisiones reales precedentes, pero no suficientemente explicitadas o tal vez ni siquiera reguladas en los cuerpos legislativos generales. De ahí que en estas Ordenanzas reales haya normas nuevas acomodadas a la vida y necesidades de aquel presidio y guarnición militar y no menos a las necesidades de las personas e instituciones que conviven en la misma ciudad con carácter más de fortaleza defensiva y de vigilancia que de centro urbano y comercial. No sorprende, por tanto, que en estas Ordenanzas, netamente militares, predominen las disposiciones relativas a la organización de la tropa, a la reconstrucción de sus fuertes y murallas y a la defensa y vigilancia de las fronteras.

A lo largo de su articulado se observan cuatro objetivos principales: 1) Llevar a cabo la reconstrucción, guarda y defensa de este bastión fronterizo puesto en peligro por los musulmanes y corsarios y, en consecuencia, garantizar la defensa de las aguas y territorios de la Corona; 2) Conseguir - mediante este ordenamiento jurídico propio que, a su vez, es local, institucional y militar - una buena administración de la plaza y el debido régimen disciplinario entre la tropa y los distintos grupos de ciudadanos: mercaderes, comerciantes, artesanos... con residencia habitual o esporádica en Bujía; 3) Dotar esta fortaleza de un ejército profesional y eficaz para los fines militares y políticos propuestos por la autoridad rea!, y 4) Cubrir determinadas lagunas jurídicas no contempladas en fueros y disposiciones precedentes y menos en el derecho general, aplicando normas adecuadas para la corrección de vicios, abusos de poder, control de sueldos y gastos, conservación de fortalezas y edificios públicos, observancia de la residencia, eficacia en los servicios, etc.

La autoría material y formal de estas Ordenanzas de carácter preceptivo y reglamentista no se debe a la intervención oficial de las Cortes o de los altos Consejos del reino, ni tampoco a la intervención de compromisarios delegados o representantes de la Corona, es más, por ninguna parte aparece el interés y ruego de la ciudad de Bujía. Se trata de una decisión personal de nuestros monarcas, perfectamente informados de la situación y necesidades de aquella plaza, con una población total de unos 10.000 habitantes entre civiles y militares que, aparte de ciudad fronteriza con su puerto, fortificaciones, castillejos, calles y plazas, era baluarte defensivo y centro de vigilancia para la guarda y control del Estrecho y de las propias fronteras del reino. La política expansionista del Emperador y sus proyectos militares no pueden descartarse entre los posibles factores influyentes, cuando no decisivos, de esta intervención regia. 
Como intervinientes principales de este ordenamiento militar, aparte de nuestros monarcas don Carlos I y su madre doña Juana - que ratifica el acta con su firma autógrafa en nombre de los dos- están el secretario real Andrés Martínez de Ondarza que dispone la escrituración por mandado de la reina y refrenda el escrito con su firma y rúbrica y, finalmente, el «procanciller» Martín Ortiz que, con firma y rúbrica personal, garantiza la autenticidad tanto del contenido documental como del sello.

\section{ESTRUCTURA DOCUMENTAL DE LAS ORDENANZAS}

El acta preceptiva de este ordenamiento regio, elaborado para la ciudad y fortaleza de Bujia, se conserva en el Archivo General de Simancas, Secc. Diversos de Castilla, legajo $48, n .^{\circ} 20$. En su versión original consta de 13 folios de papel fuerte de $305 \times 210 \mathrm{~mm}$, escritos por ambas caras en letra procesal de buena factura con numeración (foliación) romana.

En este mismo legajo, a continuación del texto original, hay dos copias coetáneas del siglo xVI, la primera simple (fasc. de 11 fols.) y la segunda notarial autorizada por R. Alcibar (fasc. de 20 fols.).

Desde el punto de vista diplomático, las Ordenanzas de Bujía de 1531 obedecen al sistema estructural clásico de la documentación real solemne con tres partes bien caracterizadas: I) PROTOCOLO INICIAL (fol. 1r.) con los siguientes apartados: «Institulación», «dirección» y "saludo»; II) TEXTO (fols. $1 \mathrm{r}-13 \mathrm{r}$ ) que comprende: «Notificación (fol. 1 r), breve "preámbulo expositivo» (fol. $1 \mathrm{r}$ ), normativa o "texto" propiamente dicho con amplio articulado, dividido en 57 párrafos o artículos (fols. $1 \mathrm{r}-13 \mathrm{r}$ ) y «dispositivo» con la orden de cumplimiento y las cláusulas conminatorias (fols. 12 v-13 r) y III) ESCATOCOLO O PROTOCOLO FINAL (fol. 13 r) integrado por: «Fecha», «suscripciones» y «sello real».

En documento aparte, pero complementario del texto y acta precedente (fol. $13 \mathrm{v}$ ), se halla la escritura notarial de recepción, juramento y debido acatamiento de dichas Ordenanzas por parte de las autoridades y representantes de SS.MM. y la promulgación de las mismas ante el pueblo y ejército mediante pregón público, elemento típico de las pragmáticas. Dicho documento complementario está fechado en Bujia el 28 de julio de 1531 y avalado con la intervención y firma autógrafa del escribano Sebastián del Castillo. Gracias a este documento complementario conocemos los nombres de las personas y cargos más representativos de la ciudad y fortaleza de Bujía en 1531. Destacan por su importancia y representatividad: Pedro Afán de Ribera, alcaide y capitán general de las for- 
talezas y responsable principal de toda la fuerza militar; Pedro de Zorita, teniente de alcaide y capitán; Diego Pérez de Lequeito, pagador general de la gente de guerra y tenedor de bastimentos y municiones; Francisco Pérez de Idiacaiz, veedor, es decir, inspector de obras, cuentas, pagas, compras y ajustes; Marcos Ruiz de Medina, contador; Francisco de Acosta, alcaide del castillejo y fortaleza menor sobre el mar; Julián de Fuentes, alcalde ordinario; Francisco de Jerez, capitán del campo; Sebastián del Castillo, escribano, y Santos de Jerez, pregonero público. No aparecen, en cambio, los nombres de los suboficiales y personal de complemento: capitanes particulares, cabos de escuadra, capellanes, cirujano, solicitador ante la Corte..., cuyos sueldos se detallan en el cuerpo de estas Ordenanzas (arts. 10-13).

El hecho de que este ordenamiento se diera no en beneficio de las personas designadas por el rey para ser sus representantes y los responsables del orden, convivencia y administración de la plaza sino en razón de algo permanente: los propios cargos y oficios del funcionariado y mandos de la ciudad y fortaleza, justifica el sistema impersonal o «innominado" utilizado por la cancillería a lo largo del texto. Se resalta, pues, el cargo, oficio e institución: alcaide, veedor, pagador, etc., pero se omite el nombre de la persona que ostenta tal cargo u oficio en el momento de promulgarse. De este modo se garantiza la vigencia ilimitada (en cuanto al tiempo) de esta normativa y, a la vez, se preven circunstancias especiales, v. gr. en caso de vacante, enfermedad, ausencia, sustitución, suplencia, etc., del titular del cargo u oficio.

Excepcionalmente y sin que exista causa especial en el artículo 2 (fol. 1 v) junto al salario del veedor de las fortalezas aparece el nombre de la persona que en ese momento (a. 1531) ocupaba dicho cargo, Francisco Pérez de Idiacaiz, que, efectivamente, coincide con el reseñado en la escritura notarial de la recepción oficial y promulgación de estas Ordenanzas (fol. $13 \mathrm{v}$ ).

1) PROTOCOLO INICIAL

a) Intitulación. Se inicia con los nombres de quienes proceden estas Ordenanzas: «Don Carlos, emperador augusto, rey de Alemania y D. Juana, su madre», reyes de España, con enumeración amplia de títulos y expresión de dominios: reinos, condados, ducados, marquesados, archiducados, etc., tanto españoles como extranjeros. La omisión de determinados títulos y señoríos se expresa al final con el clásico «etcétera».

b) Dirección. Como destinatarios de estas Ordenanzas de carácter militar aparecen, en primer lugar, la ciudad y fortaleza de Bujia y, en representación de éstas, las autoridades establecidas por el rey: el al- 
caide y capitán que ocupe dicho cargo en esta guarnición con su lugarteniente, los capitanes particulares y oficiales menores: alcaide del castillejo, alférez, cabos de escuadras..., los cargos y oficios designados por el rey para la recta administración, régimen, guarda y avituallamiento de la población y gente de guerra: el veedor, el intendente o pagador y tenedor de provisiones y material bélico y el contador y, finalmente, la tropa (soldados) y pueblo residente en la ciudad, fortalezas y en el campo.

Aunque se reseñan en forma individualizada los salarios de los distintos oficiales y de la gente de guerra, con todo, en la dirección se sigue - como advertí más arriba - el sistema impersonal o innominado.

c) Saludo. La primera parte del documento o protocolo inicial se cierra con el escueto deseo de bienestar y paz: «Salud y gracia».

II) TEXTO O CUERPO DOCUMENTAL

Consta de las siguientes partes:

1. Breve Notificación, reducida a la fórmula usual: «Sepades que...», seguida directamente de la exposición.

2. Exposición de motivos o razones que justifiquen la intervención real en la elaboración de este ordenamiento militar. Informados nuestros monarcas - se dice en la exposición de motivos en los inicios de muchos de sus párrafos- de una serie de desórdenes, injusticias, fraudes, mala administración, peligros y malestar existente entre la tropa y el pueblo residentes en Bujia y en sus fortalezas y del daño que esto suponía para el buen gobierno y servicio de dios y del reino, D. Carlos y D. ${ }^{\text {a Juana se }}$ sienten obligados a poner remedio a esta situación y con este fin establecen dichas Ordenanzas.

Como razones de peso y justificación de esta minuciosa reglamentación me permito señalar las siguientes. En primer lugar, la vinculación y permanencia de la ciudad y fortaleza de Bujía a la Corona de España desde 1510; después, su importancia estratégica y defensiva y la voluntad real de mantener y conservar aquel presidio — tal vez en peligro- para salvaguarda del Estrecho y de nuestras fronteras y, finalmente, la necesidad imperiosa de dotar a dicha plaza, a sus autoridades y funcionarios, a la tropa allí destacada y a todos sus habitantes de un estatuto juridico regulador del buen gobierno y correcta administración, orden, convivencia, abastecimiento, etc., al que en lo sucesivo deberian someterse autoridades y súbditos.

Las injusticias, abusos, fraudes, mala gestión... a que se alude en el articulado, introducidos a lo largo del tiempo en puntos tan importantes 
como la distribución equitativa de los salarios y repartos alimenticios y de ropas, el recto uso de los dineros públicos, el control de aspectos trascendentales para la convivencia, disciplina y eficacia del ejército, v. gr. las ausencias prolongadas y sin justificación, la corrupción de los soldados, debida, bien al lujo excesivo en el vestir, bien a otros vicios y excesos propios de la gente de guerra: juegos prohibidos, empeños, préstamos y adelantos, prostitución, regalos etc. requerian una normativa adecuada. Este conjunto de corruptelas, abusos y vicios perjudicaban gravemente tanto los intereses generales y particulares de los habitantes de aquella ciudad y fortaleza como los de España y de sus reyes, que debían afrontar con todos los gastos de la plaza.

3. Texto articulado, dividido en 57 artículos o párrafos, algunos de ellos con subpárrafos y todos sin numerar pero precedidos, en casi su totalidad, de signos iniciales de separación $(=v)$ a modo de gamma con valor de calderón.

Dichos párrafos o artículos, de desigual extensión, equivalen más bien a puntos o cuestiones con normativa específica y reguladora que a capitulos extensos con temática exclusiva y pormenorizada.

A lo largo de este extenso articulado se regulan los principales aspectos jurídico-administrativos y económicos relativos a la composición del ejército, regimiento y servicios, avituallamiento de la plaza, control y fijación de sueldos y precios, obligaciones de la oficialidad y de los simples soldados, regulación y vigilancia del comercio, ventas y repartos, inspección de la tropa y efectivos militares, vigilancia y corrección de los vicios más frecuentes, reparación y equipamiento de fortalezas, torres, castillejo y demás edificios destinados a vivienda, almacenaje de alimentos y armas, sanidad..., y una serie de medidas administrativas encaminadas al bienestar general, buen gobierno, eficacia defensiva y, sobre todo, a la vigilancia y control tanto de la plaza y de sus gentes como de las fronteras del reino.

A la vista de los abusos surgidos en Bujía desde su anexión a España (a. 1510) hasta el momento de la promulgación de estas Ordenanzas (a. 1531) y ante la amenaza constante de pequeños reinos africanos limítrofes y del bandidaje y piratería de Barbarroja y de otros grupos incontrolados de aventureros y tropa de saqueo y pillaje procedentes del Norte de África, a quienes se cita expresamente en el art. 18 (fol. 2 v) como enemigos de la religión y de España, nuestros monarcas consideraron indispensable: $\left.1 .^{\circ}\right)$ tener bien controlados «los movimientos e cosas que hazen e emprenden Barbarroxa e los otros turcos e moros de aquellas partes...»; $2 .^{\circ}$ ) llevar a término la reconstrucción, fortificación y defensa de esta plaza con su fortaleza mayor, castillejo, murallas defensivas y torres 
vigias, puerto, etc., y, sobre todo, $3^{\circ}$ ) conseguir -mediante rigurosos exámenes de alistamiento e inspección periódica del personal militar, material bélico y demás pertrechos propios de un presidio defensivo-- que Bujia fuera centro eficaz de control y vigilancia de las aguas y fronteras del reino.

Tras la reconstrucción y reforzamiento de la ciudad y de sus fortalezas, había que fijar el número y calidad de los hombres de guerra con sus mandos y suboficiales que pasan de 360 a 660, divididos en escuadras o batallones de: «caballería» (lanceros a la gineta), «infantería» (escopeteros, ballesteros, arcabuceros y peones piqueros), "artilleria» (artilleros), «marina» (hombres de la mar) y «hombres del campo».

No era menos importante, para la convivencia y buena administración, establecer salarios fijos y justos, aunque fueran moderados, tanto para los oficiales como para el resto de la tropa $y$, finalmente, garantizar el abastecimiento y reparto justo de víveres, ropas y enseres, así como de naves, caballos, municiones, pertrechos, etc. indispensables tanto para la defensa como para la guerra. Lógicamente nuestros monarcas querian controlar la eficacia de los servicios encomendados al personal militar y administrativo estableciendo no sólo las obligaciones y derechos correspondientes a los mandos y principales oficios sino también las de los suboficiales y soldados que, en todo momento, debian ser hábiles y estar capacitados para el eficaz desarrollo de sus funciones, someterse a los "alardes» o revisiones periódicas, observar la residencia y tener a punto sus armas, caballos y embarcaciones para la guerra.

Otro punto importante a regular — dadas las consecuencias nefastas que suponia para la disciplina y eficacia del ejército- era la frecuente malversación de sueldos, enseres y armas por parte de los soldados, acostumbrados a la adquisición de vestidos lujosos, gastos superfluos, regalos injustificados, juegos prohibidos, préstamos («pasacuentas») y adelantos, fianzas y empeños..., vicios y abusos que, con frecuencia, consentían y hasta facilitaban los propios administrativos y oficiales.

Tras establecer las medidas adecuadas para corregir semejantes defectos y abusos y, sobre todo, para sanear la administración y conseguir los fines asignados por los reyes al ejército: garantizar la seguridad y defensa de Bujia y de las fronteras colindantes, este ordenamiento concluye con un párrafo (art. 56) dedicado a la buena organización y funcionamiento del hospital de heridos y enfermos y otro final (art. 57) en el que se fija la distribución y adjudicación de las penas establecidas para los transgresores a lo largo del articulado, a saber, para la cámara real, para el hospital de la ciudad y fortaleza de Bujía, para el acusador y para el juez que sentenciare. 
4. Disposición o mandato real de cumplimiento, para lo sucesivo, de todo lo dispuesto en las Ordenanzas con revocación expresa de cualesquier privilegios, cédulas, usos y costumbres..., dados en contrario o existentes hasta aquí, conminación de penas: 50.000 maravedías para la cámara del rey y pérdida de la confianza y amistad regia para quienes se opusieran a ellas.

He aquí el resumen del dispositivo que en el texto original ocupa 13 líneas:

"Lo qual todo que dicho es, mandamos asy se haga o cumpla de aqui adelante...syn embargo de qualesquier çedulas, usos o costumbres que en contrario aya; lo qual todo rrevocamos e anulamos e damos por ninguno; e sy alguna çedula o mandamiento se diere contra estas dichas hordenanzas o contra alguna de ellas, mandamos que no sea obedecida, guardada ni cumplimentada, salvo sy en la tal çedula o mandamiento fuere inserta la hordenanza contra quien se diere y revocada expresamente. $E$ los unos nin los otros non fagades ni fagan ende al por alguna manera, so pena de la nuestra merçed e de cinquenta mill maravedis para la nuestra camara» (fols. $12 \mathrm{v}-13 \mathrm{r}$ ).

III) ESCATOCOLO con los siguientes elementos:

a) Data tópica y cronológica por el sistema moderno del nacimiento de Cristo con inclusión del nombre de la localidad, al estilo de algunas cartas de privilegio, provisiones y pragmáticas: "En la villa de Ocaña...", dia, mes y año: «diez dias del mes de mayo, año del nasçimiento de nuestro salvador the su Christo de mill e quinientos e treynta e un años».

b) Suscripciones: 1. ${ }^{a}$ Real autógrafa con firma y rúbrica exclusivamente de D. ' Juana: «Yo la Reyna»; 2. ${ }^{a}$ Por encima del sello la firma y rúbrica del secretario de SS.MM., Andrés Martínez de Ondarza, que refrenda el texto en nombre de los reyes y hace escribir estas Ordenanzas por mandado de su majestad la reina con la fórmula acostumbrada y $3 .^{a}$ Firma y rúbrica del «procanciller» Martín Ortiz, colocadas en el lateral derecho del sello en su parte inferior, cuyo apellido, por razón de la cursividad y defecto de la grafía, aparece mal transcrito en las dos copias coetáneas del original colocadas a continuación en fascículos sucesivos del citado legajo 48 n.20 del A.G.S., Secc. Diversos de Castilla, a que me he referido más arriba.

c) Sello real de placa, color rojizo - en la actualidad perdido y del que sólo queda la huella- con las armas de los reinos españoles y estados de la Casa de Austria. La desaparación total del sello circular de placa sobre papel y cera roja, de unos 90 a $100 \mathrm{~mm}$ de diámetro y el hecho de figurar como titulares de estas Ordenanzas D. Carlos y D. a Juana y, sobre todo, la amplitud de la matriz sigilográfica, la intervención del 
procanciller Martín Ortiz y la fecha en que se expide el documento (mayo de 1531) me hacen suponer que se trata no del sello personal de D. ${ }^{2}$ Juana sino del correspondiente a madre e hijo, utilizado casi ininterrumpidamente desde 1522 hasta finales de 1531 para negocios importantes ${ }^{3}$.

\section{REGLAMENTACIÓN ESPECÍFICA}

A lo largo del trabajo he aludido a la reglamentación global recogida en los 57 artículos de que se componen estas Ordenanzas. La imposibilidad de publicar - por razones obvias de extensión- el texto completo de las mismas en cualquier tipo de actas ${ }^{4}$, me obliga a resumir en unos cuantos apartados, siempre con referencia directa a los artículos correspondientes, los principales puntos 0 , mejor, temas regulados en este ordenamiento.

1. Número total de personal militar (600 hombres de guerra) con especificación de las diversas fuerzas integradas en el ejército destacado en Bujia: caballeria, infantería, artillería, marina y hombres del campo, y cualidades exigibles a todo soldado: edad, experiencia, habilidad y profesionalidad (Preámbulo y exposición de motivos, fol. $1 \mathrm{r}$, arts. 1-7, 9, 12 , $24,26)$.

2. Fijación de soldadas y salarios de oficiales, administrativos, personal de complemento, suboficiales, soldados y expertos (arts. 1-4, 30-31, 42-45).

3. Armamento, material de defensa y centros de almacenaje y sanidad (arts. 15-22, 29, 35, 50, 56).

4. Avituallamiento general de la plaza, a precios justos y abundante para toda la tropa, incluyendo en ésta a familiares, criados, escuderos y mozos (arts. 14-25, 29-32, 34).

5. Obligaciones especificas de la oficialidad, personal administrativo y gerente de guerra desiganda poi los monarcas: a) juramento de fidelidad y servicio a la Corona, a estas Ordenanzas y a las distintas provisiones y mandados enviados por SS.MM. Ios reyes (arts. 19-21); b) rectitud en las gestiones administrativas anejas al cargo e intervención responsable en las pruebas previas y exámenes de reconocimiento, admisión y des-

\footnotetext{
3 Arribas Arranz, F., Sellos de placa de las cancillerias regias castellanas. Valladolid 1941, págs. 158-170.

${ }^{4}$ El texto complemento de estas Ordenanzas acaba de aparecer en otro trabajo complementario que publico en la Revista de Historia Militar, n. 71, 2. semestre. Madrid 1991, pág. 105-145, bajo el titulo: “Ordenanzas Militares de Bujia de 1531».
} 
pido de suboficiales, expertos y soldados, así como en los alardes periódicos, en la entrega de pagas, repartos de provisiones y concesión de permisos (arts. 18-25, 27, 37-41, 45-49); c) vigilancia de la plaza y fronteras y también de los hombres de guerra e instrumental bélico, sin descuidar a los espias, vendedores ambulantes, esclavos, moros sueltos y grupos de ladrones y salteadores de tierra y mar (art. 42); d) control de precios, mercados, obras y establecimientos, tanto oficiales y fijos como privados y ambulantes (arts. 43, 45-47); e) cobranza de impuestos y derechos correspondientes a la Corona (art. 48); f) jusitificación documental, mediante contratos escritos y libros de control y contabilidad del empleo de los dineros públicos destinados a salarios, adquisición y reparto de víveres y provisiones, venta de alimentos, ropas y demás enseres y útiles para la defensa, contratos de obras y reparaciones de muros y edificios, distribución del personal de guerra en la fortaleza mayor, castillejo y demás puntos estratégicos de la ciudad y plaza (arts. 15-23, 25-27, 40, 45-49).

6. Puestos y lugares recomendados para la compra y trasporte de viveres y ropas: trigo, harina, cebada, vino, queso, tocino, legumbres... y demás cosas y enseres necesarios para el mantenimiento y provisión de la gente de guerra (arts. 33-36). Se señalan, de modo especial, los puertos de Málaga y Cartagena; las islas de Mallorca, Menorca, Ibiza y Cerdeña como centros idóneos para la adquisición de alimentos, y las tierras de Alicante, Baeza, La Mancha, Córdoba y Toledo para lo relativo a ropas corrientes de trabajo y vestidos de calle.

7. Libertad a todo el personal militar y civil, para escribir, informar y recurrir al rey y a su Consejo de guerra y, a la vez, para recibir correspondencia oficial, siempre que lo creyesen conveniente, útil o necesario, máxime en momentos de peligro, en asuntos tocantes a la guarda y defensa de la plaza y fronteras y en lo relativo a alteraciones graves del gobierno y administración, provocadas por desajustes, abusos e insurrecciones (arts. 27, 48, 50).

8. Castigos y penas pecuniarias para los transgresores de las distintas normas disciplinarias establecidas en este ordenamiento e, igualmente, para cuantos se opusiesen a las propias Ordenanzas, con aplicación de lo recaudado por estos conceptos (multas) a fines concretos (arts. $28,37,49,53,57)$.

9. Abusos de las autoridades: alcaide, capitanes particulares, veedor, pagador y tenedor de bastimientos, etc. en lo tocante a equidad y justicia en la distribución de soldadas y salarios, en los precios de compras y ventas, medidas y calidad de los productos, en el trato con la gente de guerra y comerciantes y en los gastos públicos (arts. 28, 32-34, 37-40). 
10. Principales vicios de la tropa y defectos a corregir: ausencias demasiado frecuentes, largas e injustificadas; excesos en la práctica de determinados juegos de azar y de envite, muchos de ellos prohibidos («tablajeros»), lenguaje blasfemo y soez, compraventas y empeños de raciones alimenticias, salarios, ropas y útiles militares, a precios excesivamente bajos; gastos superfluos en regalos y adquisición de prendas de vestir demasiado lujosas y finas para hombres de guerra, v. gr. sedas, demascos, rasos, terciopelos, tafetanes, granas, etc. y, finalmente, utilización de anticipos y préstamos («pasacuentas») con cargo a salarios aún no ganados y endeudamientos indebidos..., causas frecuentes de emprobecimiento y miseria de los soldados (arts. 28, 32, 36, 49, 51-52) ${ }^{5}$.

11. Administración y sostenimiento del hospital de heridos y enfermos de Bujía (arts. 56-57).

\section{CONCLUSIONES}

a) El ordenamiento dado a la ciudad y fortaleza de Bujía por los reyes Carlos I, y su madre, D. ${ }^{2}$ Juana, pertenece a la categoría jurídica de “ordenanzas mayores», es decir, de origen real y, hoy por hoy, las más antiguas que se conocen de esta plaza fuerte.

b) Su normativa, alejada ya del localismo foral y urbano-concejil, cae por completo dentro del campo reglamentista con marcado carácter militar y, en consecuencia, su alcance jurídico, aunque importante, no pasa de complementario de la legislación general (Derecho civil y penal) y, en

\footnotetext{
${ }^{5}$ Es curioso observar en estas Ordenanzas de 1531 la omisión total de normas sobre preceptos religiosos: confesión, misa dominical y fiestas de guardar, etc que aparecen en las de 1536-40 (AGS, Secc. Diversos de Castilla, leg. 48, n. 21). No se mencionan tampoco vicios tan frecuentes entre la gente de guerra y ambientes de presidios y fortalezas, como la prostitución y el trato con mujeres de mala vida, a pesar de figurar entre el personal de complemento 3 capellanes castrenses y existir (arts. 32, 36, 39, 49) indicios claros de tales vicios. Sabemos, no obstante, por las declaraciones de costumbres y ordenanzas complementarias, dadas pocos años después a la ciudad y fortaleza de Bujía (1536-40) durante los mandatos de D. Alejo Salgado Correa, corregidor y juez de residencia de dicha plaza, y de los alcaides y capitanes de la misma, D. Juana de Vallejo Pacheco, D. Antonio López de Vargas y D. Luis de Peralta, que tales puntos y los relativos a juegos prohibidos, lujo en el vestir, regalos y empeños, fueron objeto de minuciosa regulación. A esta segunda relación y etapa corresponden también los relativos a la salud pública e higiene, control de actividades de gremios y oficios textiles, seguridad ciudadana, precios y mercados de frutas, verduras, hortalizas, carnes y pescados. Un comentario detallado sobre dichas prescripciones puede verse en el trabajo de la Dra. López Beltrán, citado en nota 1.
} 
cuanto a territorialidad, sin perder de vista la ciudad y fortaleza de Bujía, se ciñe preferentemente a un colectivo concreto: "los hombres de guerra», destacados como guarnición militar en aquella plaza fuerte, ruta de nuevas conquistas, puerto de travesia y presidio de control entre España, Argelia y las distintas ciudades, pueblos y grupos del Islam.

c) Gracias a estas Ordenanzas militares de 1531 conocemos numerosos aspectos económicos, administrativos, disciplinares, sociales, militares, etc. de gran interés histórico. Quizás los más importantes sean los relativos a la situación y defensa de dicha plaza, número de soldados y clases de tropa, armamento y útiles defensivos, sueldos en dinero, ropas y víveres para cada uno de los hombres de guerra, según su graduación y oficio, forma normal de avituallamiento y mercados de adquisición, subvenciones para reparos de fortificaciones, edificios públicos, viviendas y sostenimiento del hospital.

Pero lo más llamativo de esta normativa es la minuciosidad y precisión con que se tratan no sólo los asuntos importantes, v. gr. control de gastos para mantenimiento, actualización y profesionalidad del ejército y demás servicios extraordinarios de guerra y espionaje, derechos y obligaciones de los mandos y oficiales, cualidades exigidas a los soldados para poder continuar en filas o incorporarse de nuevo a ellas, abusos de las autoridades y administrativos..., sino también los relativos a detalles aparentemente de escasa entidad, v. gr. defectos y vicios más frecuentes de la tropa, revisión de armas y útiles defensivos y de guerra, número de sirviertes y de acompañantes permitidos al alcalde y altos cargos administrativos del ejército (art. 25), penas establecidas para los infractores de los distintos artículos de estas Ordenanzas, libertad por parte de súbditos y soldados para escribir, informar y acudir al rey o recibir su respuesta, sobre todo en peligro de invasión, guerra, desorden o injusticia; vigilancia de moros sueltos, y de comerciantes y espias que frecuentan la ciudad o deambulan por sus calles; control de juegos, préstamos y endeudamientos que conducen al empobrecimiento y miseria de muchos soldados y especial cuidado del hospital general ${ }^{6}$.

\footnotetext{
${ }^{6}$ El texto completo de estas RR. Ordenanzas de Bujia de 1531, precedido de breve introducción histórico-diplomática y lexicografia, puede verse publicado en Revista de Historia Militar, n. 71 (2." Semestre) Madrid 1991, pp. 105-145.
} 